Article

\title{
Detecting Tree Stems from Volumetric TLS Data in Forest Environments with Rich Understory
}

\author{
Johannes Heinzel * and Markus O. Huber \\ Swiss Federal Institute for Forest, Snow and Landscape Research WSL, Zürcherstraße 111, \\ 8903 Birmensdorf, Switzerland; markus.huber@wsl.ch \\ * Correspondence: johannes.heinzel@wsl.ch; Tel.: +41-44-739-2238 \\ Academic Editors: L. Monika Moskal, Clement Atzberger and Prasad S. Thenkabail \\ Received: 19 August 2016; Accepted: 21 December 2016; Published: 28 December 2016
}

\begin{abstract}
The present study introduces a method to identify tree stems from terrestrial laser scanning (TLS) data. We focused on forest environments of diverse and layered structure, which were technically characterized by strong occlusion effects with regards to laser scanning. The number and distribution of tree stems are important information for the management of protective forests against natural hazards, for forest inventory, and for ecological studies. Our approach builds upon a three-dimensional (3D) voxel grid transformation of the original point cloud data, followed by two major steps of processing. Firstly, a series of morphological operations removed leaves and branches and left only potential stem segments. Secondly, the stem segments of each tree were combined by a multipart workflow, which uses shape and neighborhood criteria. At the same time, erroneous fragments and noise were removed from the dataset. As a result, each object in the voxel grid was represented by a single connected component referring to one specific tree stem. Testing the method on nine spatially independent plots provided detection rates of $97 \%$ for the number and location of stems from mature trees with a diameter $\geq 12 \mathrm{~cm}$ and $84 \%$ for smaller trees with a minimum of $130 \mathrm{~cm}$ total tree height. In summary, we obtained a dataset covering the number and locations of the stems from both mature and understory trees, while not aiming at a precise reconstruction of the stem shape.
\end{abstract}

Keywords: terrestrial laser scanning; regeneration; mathematical morphology; occluded tree stems; tree position; forest inventory

\section{Introduction}

Ground based remote sensing techniques, like terrestrial laser scanning (TLS), are often advantageous for structures that are difficult to observe from a bird's eye perspective. For layered forests with a strong understory, vegetation objects, such as tree stems, can be better observed by TLS compared to airborne laser scanning (ALS). In this study, we work with data from multilayered forest stands, where the understory layer tends to occlude the stem surface from the laser beam. The physical structure of the forest as the object of technical observation has direct effects on data acquisition and data analysis. Due to the different perspective of TLS and the closer distance to the objects, higher point densities and higher levels of detail can be achieved. Several authors confirmed these considerations. Hilker et al. [1] explained why ALS is largely insensitive for below canopy vegetation objects and investigated differences in return distribution between ALS and TLS data. Murgoitio et al. [2] recommended TLS for sub-canopy metrics to compensate vegetation obstruction from ALS, while pronouncing the advantage for the discrimination of trunks. White et al. [3] summarized the advantages of TLS for assessing woody forest components, but also pointed to recent developments in ALS techniques, which could increase its capacity for detecting below canopy vegetation elements. Based on the prevailing advantages of TLS, only a few authors such as 
Reitberger et al. [4] attempted to detect tree stems from ALS data. Some studies gained general stem related information from ALS data without detecting the stems themselves, but derived it indirectly from other metrics [5,6].

The general constrains of ALS in stem detection are even more serious for smaller trees of the regeneration and understory layers of a forest stand. Therefore, automatically deriving stem information from TLS can serve specific needs of forest science. Managing the multifaceted functions of a protection forest demands reliable information on tree stems and their spatial distribution. Stem spacing and stand density are important parameters of the protective function of forests against rockfall and snow avalanches in alpine regions [7]. Several authors confirmed the importance of the horizontal forest structure for effective hazard protection, including regeneration trees for long-term stability [8-10]. However, for forest inventory, the total stem number and the stem distribution are also useful and additional sources of information [11]. While for inventory purposes, TLS derived stem information often concentrates on traditional parameters such as diameter at breast height (DBH) of mature trees $[3,12]$, TLS is further capable of providing complete stem distribution mappings, including regeneration trees. Stem mappings are also often required for ecological studies, for example, in the context of investigations of leaf area and light use efficiency [13] or investigations that address competition indices [14]. Conventional field collection of such data, for example, the mapping of tree stem locations using the Global Navigation Satellite System (GNSS) or traditional surveying techniques, is often difficult and laborious, especially in mountainous regions and forests with understory layers.

Forest related applications demand different types and levels of detail for stem information. Reflecting these needs, current research approaches derive two major groups of tree stem information from both ALS and TLS data. The first type of approach derives the location and the number of stems and approximates the extent of the stem from trees situated in a forest environment. The second type focuses on the isolation of the complete stems in detail, sometimes also together with the branches. It generally aims at detailed modeling of stems and branch architecture, which could be used for biomass estimation [15], for deriving indicators of wood quality by using stem metrics together with the location of branch attachments [16,17], or for three-dimensional (3D) radiative transfer modeling [18]. For 3D radiative transfer modeling, Schneider et al. [18] achieved better results with voxel data than with an individual tree approach using predefined crown shapes. Both types of approaches also differ in the environmental and spatial context being observed. While the first type provides information that refers to a forest stand, the second type mostly applies for isolated single trees not related to any forest environment. Examples for the forest environment related approach are as follows: Lovell et al. [19] identified only the lower parts of the stems for DBH estimation, Reitberger et al. [4] combined stem detection with single tree segmentation, Kelbe et al. [20,21] focused on stems from mature trees in forest environments, Eysn et al. [22] detected spruce stems in a stand with minimally occluded trees, and Yao et al. [23] verified their stem detection results after adjusting the reference tree count for occlusion effects. A special application outside the forestry domain is described by McDaniel et al. [24], who used stem locations for position tracking of unmanned ground vehicles. Studies for detailed stem reconstruction on isolated trees are from Raumeonen et al. [25] and Hackenberg et al. [26], who worked with single trees scanned from multiple positions, Bucksch and Fleck [27] focused on reconstructing the complete branch structure, and Gorte and Pfeifer [28] and Hosoi et al. [29] used morphological approaches with voxel data. Recently, detailed tree reconstruction has also been applied to multiple trees extracted from a forest stand. This especially refers to so-called quantitative structure models, which have been used by Calders et al. [15] and Raumeonen et al. [30]. Until now, these multiple tree models have only been applied to relatively open forest stands with loose standing and isolated trees. Manual interaction might still be required to separate vegetation parts of neighboring trees [15]. Also, Kelbe et al. [31] described a first approach for quantitative stem modeling within a forest stand and focused on mature trees. Generally, stem detection from LiDAR data can be challenging in forest conditions with a strong understory or regeneration layer. Such conditions produce a high number of low branches, which occlude the tree stems [24]. This effect of occlusion 
is increased by the short distance and the low observation angle to close-by tree objects of the TLS systems [24]. Situations are even more complicated in the foliated vegetation period of deciduous or mixed stands. For this reason, many approaches for stem detection in forest environments concentrated on free-standing mature trees. Only a few studies exist that tried to detect stems that were occluded by understory layers or regeneration trees, as for example Brolly et al. [32] and Xia et al. [33]. While both studies are innovative in their field, they dealt with simplified scenarios. Brolly et al. [32] worked with homogenous regeneration patches only, excluding mature trees. It also remains unclear if they used data from foliated or non-foliated trees. Xia et al. [33] used a single frontal perspective scan and only validated those tree stems that were visible from the scanners point of view. The method was only tested on two scenes with apparently weak understory density.

For situations of forest conditions with a distinct understory, which are technically difficult for data analysis, existing methods are not sufficient and a clear research gap exists. Instead of more precise tree modeling, for such forests the focus should be, as much as possible, on a complete detection of all stems, independent from the tree size and forest layer. The regeneration trees from the undergrowth have been largely ignored until now. For example, information on complete stem distribution, including regeneration trees, is an important basis for an effective management of protection forests. This is where the present study presents an application-oriented method to derive area-wide stem locations and stem distribution of both understory and mature trees. It introduces an alternative approach for existing methods in order to improve the detection of tree stems in such technically difficult forest conditions. While the majority of the existing approaches build on geometric analysis of point clouds, volumetric voxel grid analysis and the use of techniques from mathematical morphology have been explored far less for TLS tree stem detection. Novelties of our approach are the application of a series of spatially-variant and directional openings together with 3D connectivity and neighborhood analysis. We considered the whole vegetation complex as a volume-like structure and used multiple scan positions, which enabled the point data transfer into volumetric voxel grids. TLS data was captured on nine plots, located inside different forest stands. The stands mostly contained mixed to coniferous forest with different understory structures and were in a foliated state. Many stems were at least partly occluded by foliage and branches of the understory. The goal of the presented approach is to detect and locate all tree stems while not aiming at a detailed reconstruction of their shape. In addition to the mature tree stems, we also tested our algorithm on the smaller regeneration trees. The method builds upon a voxel representation of the original point data and can be subdivided into two subsequent parts of processing, which are the detection of initial stem segments and the combination of the segments to individual tree stems.

\section{Study Area and Data}

\subsection{Test Site}

All data was collected in mixed and coniferous forests in the canton of Grisons in Switzerland. The data has been captured on spatially separated plots of roughly square shape with $25 \mathrm{~m}$ edge length. The squares were oriented towards north, as can be seen from the scheme in Figure 1. The center of the plot was marked in the ground by a buried steel rod and represented the location of a permanent sample plot of the Swiss national forest inventory (NFI) or the regional inventory of Grisons.

In order to test our method, it was applied on plots of diverse forest structures. The dense vegetation structure on many plots is expressed by visual obstructions from concentrated vegetation biomass from foliage and branches in the lower and mid forest layers. However, the plots for data acquisition were originally not selected to be used for tree stem detection. Therefore, for the present study, limitations in the choice of available scanning plots were given by the availability of reference data. Table 1 provides an overview of the structure and forest characteristics of these plots, for both mature and regeneration trees. The main tree species were Norway spruce (Picea abies L. H. KARST.), common beech (Fagus sylvatica L.), silver fir (Abies alba MiLl.), larch (Larix spp.), 
and Scots pine (Pinus sylvestris L.); less abundant were ash (Fraxinus spp.), maple (Acer spp.), rowan (Sorbus aucuparia L.), other Sorbus spp., alder (Alnus spp.), oak (Quercus spp.), and poplar (Populus spp). For the mature trees, the number and the species compositions are given. The total number of mature trees differentiates between two groups of $\mathrm{DBH}$, starting with a minimum diameter of $12 \mathrm{~cm}$. For the smaller regeneration trees, the species-specific canopy density was available instead of the total tree numbers. The canopy density is given in percentage of ground area coverage and refers to a single plot quadrant as indicated in Figure 1. Since, for the regeneration trees, no total number of trees was available, a measure for the stem density cannot be provided. Table 1 differentiates the canopy density for tree heights below $1.3 \mathrm{~m}$ and for tree heights above $1.3 \mathrm{~m}$ but smaller than $12 \mathrm{~cm}$ of DBH. For overview reasons, only the highest canopy density, occurring in at least one of the quadrants, is shown. In order to reduce the large number of tree species with low canopy coverage, we further restrained the listing to those species with more than $5 \%$ canopy coverage.

Table 1. Overview about the forest structure and composition on the test plots. For mature trees, individual tree information is regularly recorded by the forest inventory. For regeneration trees, only species specific canopy coverage was available. DBH stands for diameter at breast height.

\begin{tabular}{|c|c|c|c|c|c|}
\hline \multirow[b]{2}{*}{ Plot } & \multicolumn{2}{|c|}{ Mature Trees } & \multicolumn{2}{|c|}{$\begin{array}{l}\text { Regeneration Trees Canopy Coverage } \\
\text { (Species }>5 \% \text { ) }\end{array}$} & \multirow[b]{2}{*}{ General Description } \\
\hline & Number of Trees & Composition & Tree Height $\leq 1.3 \mathrm{~m}$ & $\begin{array}{l}\text { Tree Height } \\
>1.3 \mathrm{~m} \text { and } \\
\mathrm{DBH}<12 \mathrm{~cm}\end{array}$ & \\
\hline 1 & $\begin{array}{l}7 \mathrm{DBH} 12-36 \mathrm{~cm} \\
4 \mathrm{DBH}>36 \mathrm{~cm}\end{array}$ & $\begin{array}{c}\text { Fir: } 5 \\
\text { Pine: } 1 \\
\text { Spruce: } 3 \\
\text { Beech: } 2\end{array}$ & Fir $6 \%-15 \%$ & $\begin{array}{l}\text { Fir, } 16 \%-25 \% \\
\text { Spruce } 6 \%-15 \% \\
\text { Beech } 6 \%-15 \%\end{array}$ & $\begin{array}{c}\text { Medium vegetation density below } \\
1.3 \mathrm{~m} \text {. Many trees between } \\
1.3 \mathrm{~m} \text { and } 4 \mathrm{~m} .\end{array}$ \\
\hline 2 & $\begin{array}{l}8 \mathrm{DBH} 12-36 \mathrm{~cm} \\
9 \mathrm{DBH}>36 \mathrm{~cm}\end{array}$ & $\begin{array}{c}\text { Pine: } 4 \\
\text { Spruce: } 8 \\
\text { Beech: } 2 \\
\text { Ash: } 1 \\
\text { Dead (standing): } 2\end{array}$ & $\begin{array}{l}\text { Beech } 16 \%-25 \% \\
\text { Other deciduous } \\
\text { trees } 6 \%-15 \%\end{array}$ & $\begin{array}{l}\text { Beech } 26 \%-50 \% \\
\text { Elm } 6 \%-15 \%\end{array}$ & $\begin{array}{l}\text { High vegetation density below } \\
1.3 \mathrm{~m} \text {. Many trees with } \\
\mathrm{DBH}<12 \mathrm{~cm} \text { are very high. }\end{array}$ \\
\hline 4 & $\begin{array}{l}10 \mathrm{DBH} 12-36 \mathrm{~cm} \\
7 \mathrm{DBH}>36 \mathrm{~cm}\end{array}$ & $\begin{array}{c}\text { Pine: } 11 \\
\text { Spruce: } 4 \\
\text { Beech: } 1 \\
\text { Dead (standing): } 1\end{array}$ & All species $\leq 5 \%$ & $\begin{array}{c}\text { Fir } 16 \%-25 \% \\
\text { Spruce } 26 \%-50 \% \\
\text { Beech } 16 \%-25 \%\end{array}$ & $\begin{array}{l}\text { Medium vegetation density below } \\
1.3 \mathrm{~m} \text { with singular species. } \\
\text { Smooth transition between mid } \\
\text { and upper canopy layer. }\end{array}$ \\
\hline 5 & $\begin{array}{l}15 \mathrm{DBH} 12-36 \mathrm{~cm} \\
3 \mathrm{DBH}>36 \mathrm{~cm}\end{array}$ & $\begin{array}{c}\text { Pine: } 3 \\
\text { Spruce: } 1 \\
\text { Larch: } 4 \\
\text { Beech: } 5 \\
\text { Ash: } 4 \\
\text { Other con.: } 1\end{array}$ & $\begin{array}{l}\text { Ash } 51 \%-75 \% \\
\text { Maple } 6 \%-15 \%\end{array}$ & $\begin{array}{c}\text { Ash } 6 \%-15 \% \\
\text { Beech } 16 \%-25 \%\end{array}$ & $\begin{array}{l}\text { High vegetation density in all } \\
\text { heights. Borders between canopy } \\
\text { height levels are vanished. }\end{array}$ \\
\hline 8 & $\begin{array}{l}3 \mathrm{DBH} 12-36 \mathrm{~cm} \\
3 \mathrm{DBH}>36 \mathrm{~cm}\end{array}$ & Spruce: 9 & All species $\leq 5 \%$ & Spruce $16 \%-25 \%$ & $\begin{array}{l}\text { Only coniferous trees. Patchy } \\
\text { distribution of trees with high } \\
\text { density inside the patches. }\end{array}$ \\
\hline 9 & $12 \mathrm{DBH}>36 \mathrm{~cm}$ & Spruce: 12 & Rowan $16 \%-25 \%$ & $\begin{array}{l}\text { Spruce } 6 \%-15 \% \\
\text { Rowan } 16 \%-25 \%\end{array}$ & $\begin{array}{l}\text { Only spruce mature trees. Many } \\
\text { trees below } 12 \mathrm{~cm} \text { DBH and of } \\
\text { moderate height above } 1.3 \mathrm{~m} .\end{array}$ \\
\hline
\end{tabular}




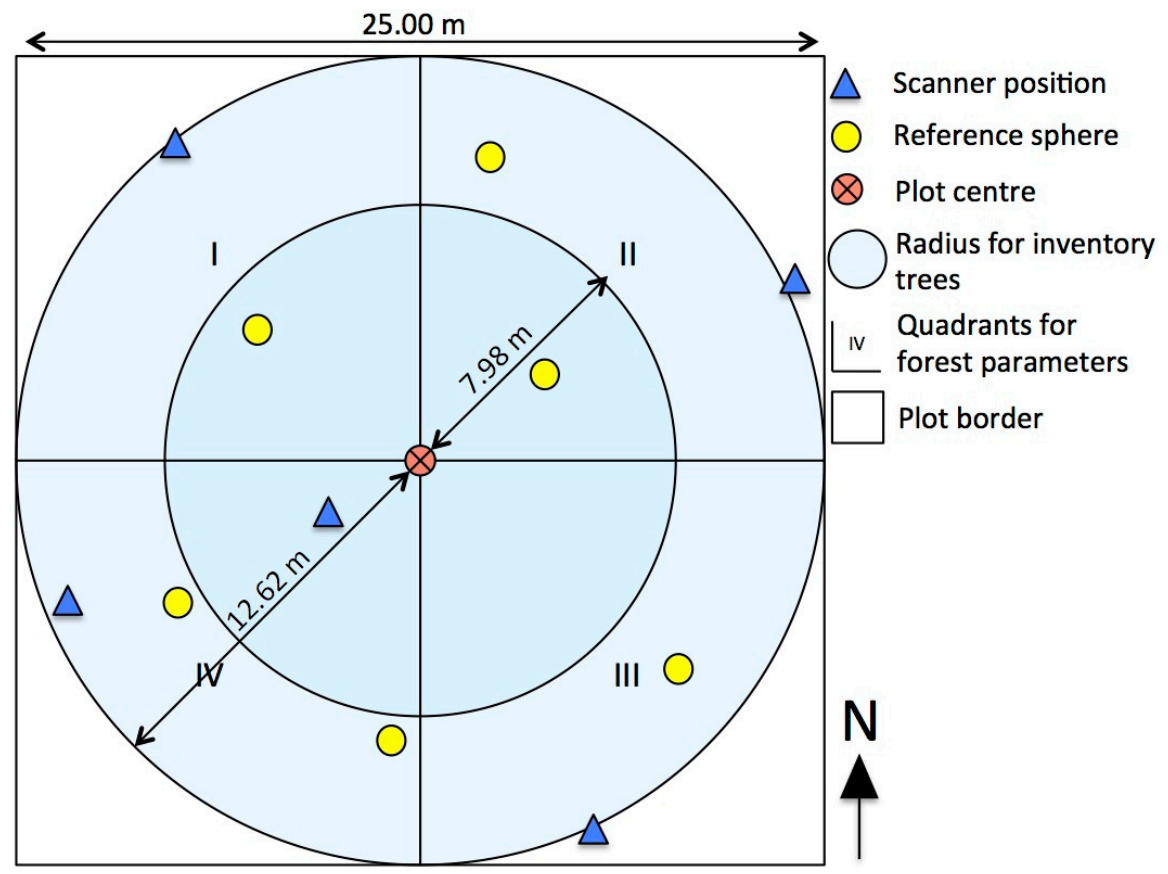

Figure 1. Schematic setup of a plot for scanning and reference data collection. Each plot was centered on an inventory point marked in the field and bordered by a square of $25 \mathrm{~m}$ edge length. The scanner positions and reference spheres were distributed over the plot to minimize shadowing effects. The two radii are used by the Swiss forest inventory to measure the positions of mature trees.

\subsection{LiDAR Data}

On each plot, a number of five scan positions were used to achieve a reasonable balance between the effort of work and to minimize occlusion effects. Typically, a pattern was followed with one scan near the center and four scans distributed close to each corner (see Figure 1). This pattern was chosen based on experimental tests and experience, but a similar scan setup was also introduced before by Yao et al. [23] and van der Zande et al. [34] and denoted as corners setup. Depending on terrain characteristics, small deviations from the setup pattern could be required. For registration of the single scans into a common coordinate system, six spheres were distributed over each plot and mounted on ranging poles. For georeferencing the data, a long-term GNSS measurement of at least 30 minutes was recorded for a single arbitrary position on each plot. Post-processing of these measurements was conducted using close-by virtual reference stations, which were provided as a service from the Swiss Federal Office of Topography. This produced differentially corrected positions of, on average, $10 \mathrm{~cm} \pm 10 \mathrm{~cm}$ of accuracy. The positions of all objects on the plot were determined relative to that reference position by measuring the azimuth, the distance, and the vertical dip.

For the present study, a FARO Focus 3D S120 scanner was used. Table 2 lists the general specifications of the scanner together with the specific configuration for all scans in this study. 
Table 2. General scanner specifications and individual configuration.

\begin{tabular}{cc}
\hline \multicolumn{2}{c}{ FARO Focus 3D S120 } \\
\hline \multicolumn{2}{c}{ General Specification } \\
\hline Range & $0.6 \mathrm{~m}-120 \mathrm{~m}$ \\
Ranging error & $\pm 2 \mathrm{~mm}$ \\
Laser wavelength & $905 \mathrm{~nm}$ \\
Beam divergence & $0.19 \mathrm{mrad}$ \\
Beam diameter at exit & $3.0 \mathrm{~mm}$, circular \\
Color unit & Up to 30 megapixels, RGB \\
\hline \multicolumn{2}{c}{ Scan Configuration } \\
\hline Point distance (mm/10 m) & 6.136 \\
Resolution (MPts) & 44 \\
Scan size (Pt) & $10,310 \times 4268$ \\
\hline
\end{tabular}

\subsection{Reference Data}

As reference, data we used datasets which were recorded during a field campaign and at the same time as TLS data. Both the scans and the reference data were acquired in summer 2015 during the vegetation period with deciduous trees being fully foliated. Reference data was recorded for general purposes and not specifically for stem detection. However, two of the sub-datasets were well suited for verifying the stem locations. The first one included the stem positions at breast height $(130 \mathrm{~cm}$ above ground) for all mature trees, which are regularly observed by the forest inventory. Since the inventory samples the trees within two concentric circles, the mature trees were subdivided into two categories. Category one contained all trees with a DBH of at least $12 \mathrm{~cm}$ and located within the inner concentric circle of $200 \mathrm{~m}^{2}$. Category two contained all trees with a DBH of $36 \mathrm{~cm}$ or more and located within the outer concentric circle of $500 \mathrm{~m}^{2}$. Altogether, we had a set of 77 inventory trees from the inner circles and 37 trees from the outer circles from all nine plots for verification.

The second reference dataset contained data from regeneration trees only, which were selected randomly in the field with an arbitrary number of stems for each plot. Only trees with a minimum crown top height of $10 \mathrm{~cm}$ and a maximum DBH of $12 \mathrm{~cm}$ were selected. Due to the general purpose of the reference data, no specific stem information was available for the regeneration trees except for the location and the extent of the tree crowns. For each regeneration tree, the horizontal position of the crown center and the smallest crown diameter, determined from a horizontally projected crown contour, have been measured. Only in cases of slanted trees with the stem bases being outside the crown radius were the coordinates of the foot stems recorded. To filter small shrubs and grass and to ensure a minimum length of a vertically distinctive stem, we removed all trees with a crown top height smaller than $130 \mathrm{~cm}$. The stems of those small trees are technically undetectable for our algorithm, since crown bases are low and the remaining stem segments are not distinct enough or too small for the morphological operations. From all nine plots, 65 regeneration trees remained for verification.

\section{Method}

The present method of tree stem detection builds upon a voxel grid representation of the original scan data. In comparison to vector-based approaches that build on point coordinates, we make use of the characteristics of gridded data representations. Similar to two-dimensional (2D) images, voxel grids provide order and regularity in the form of a lattice structure to the data, which can be used for specific processing techniques in analysis. Due to the long tradition of 2D-image pattern recognition, a wide variety of algorithms have been developed in that field. Many of these algorithms have been transferred or are generally transferable from $2 \mathrm{D}$ to $3 \mathrm{D}$ grids. The presented method builds on algorithms from $3 \mathrm{D}$ mathematical morphology as an alternative approach to point cloud based methods. It includes logical processing chains by making use of the ordered grid structure, which is characterized by a discrete 
topology of the data and the principles of connectivity and adjacency. While many studies on tree stem detection applied classification and shape fitting algorithms to the point cloud $[4,20,26,33,35]$, only a few studies follow morphological approaches on voxel grids [28,29,32]. These studies give an indication that morphological methods have good potential to extract stems from layered forest structures and should be observed further.

The presented method consists of two major parts. The first one refers to the detection of stem segment candidates by morphologically separating them from other objects in their direct neighborhood, which mainly refers to dense clusters of leaves, needles, and branches. The second part filters false non-stem objects and noise, while the remaining segments are combined in cases where they can be logically assigned to the same tree stem.

\subsection{Preprocessing}

Before analysis of the volumetric voxel grids, LiDAR point cloud data, as extracted from the original signal by the scanner system, must be preprocessed. The preprocessing is conducted in multiple steps to produce an appropriate form of the dataset for subsequent transformation and analysis.

As a first step, the single scans within each plot were co-registered by matching the strongly reflective spheres as common targets between the scans. Six spheres with a diameter of $145 \mathrm{~mm}$ were distributed over each test site beforehand, of which at least three must be visible in each pair of scans. Registration was carried out using the software FARO Scene, which is designed to work with the scanner in use. Georeference was assigned to the dataset by using the reference GNSS position of each plot together with the relative position of the reflective targets.

Further preprocessing steps included the 3D-thinning of the point clouds with 1 point $/ \mathrm{cm}^{3}$, the merging of single scans, the clipping to the plot edge, and the transfer into a voxel grid. As result, we received one binary voxel grid for each plot, with the value 'True' being assigned to voxels including a LiDAR reflection, and 'False' to those being empty. After testing different grid resolutions, it was empirically decided that a voxel size of $5 \mathrm{~cm}$ was most appropriate. Visual comparison of different voxel sizes revealed that larger voxels tended towards clumping with non-stem voxels and smaller voxels resulted in more gaps between the segments. Béland et al. [36] reported partly similar criteria when optimizing the voxel size for determining leaf area distribution. For the present study, the limiting factors for the voxel size were, firstly, the minimum size of the tree stems in combination with the shape and size of the morphological structuring elemenst and, secondly, the spacing of original LiDAR beams. Figure $2 \mathrm{a}, \mathrm{b}$ shows the original and the preprocessed data, respectively. The first image illustrates the original point cloud of a single roughly square plot. For visualization reasons, the points are colored using RGB photographs. The upper parts of the tree crowns are overexposed to the sunlight and appear almost white. The second image shows the voxelized data, visualized as a volumetric voxel grid. The voxels are colored with the intensity values of the reflections for better visual appearance and are displayed with a scaled transparency. All subsequent procedures for stem detection are solely built upon the volumetric voxel grids. 

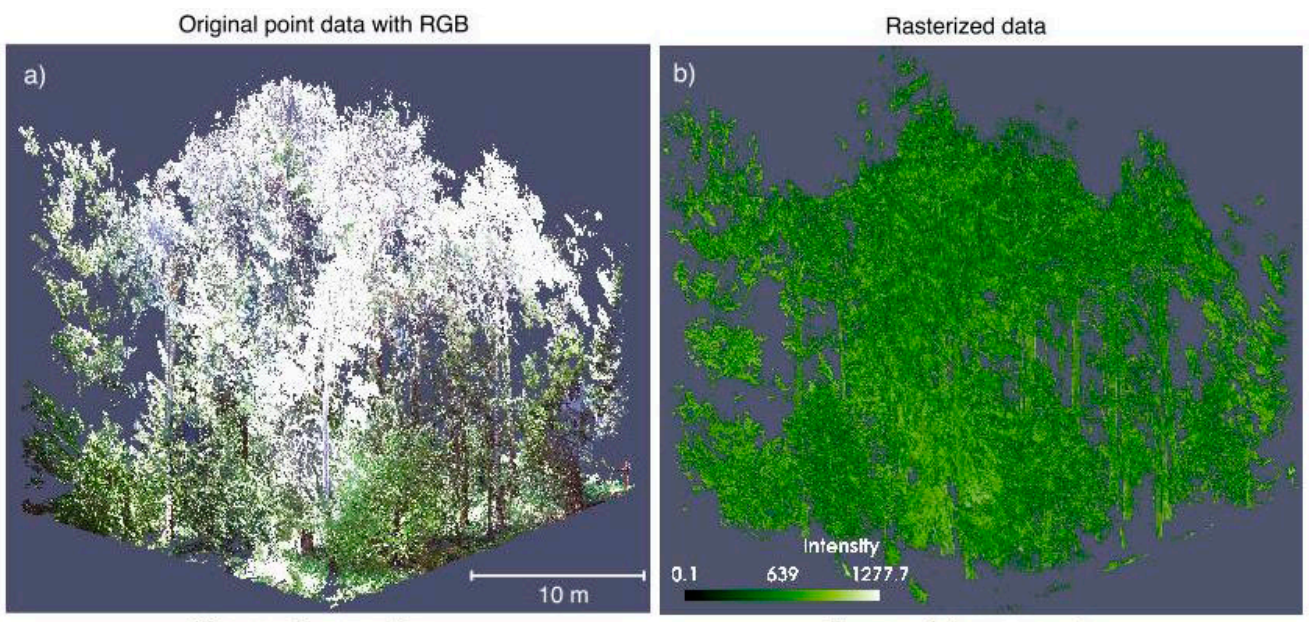

After opening operation

Processed stem segments
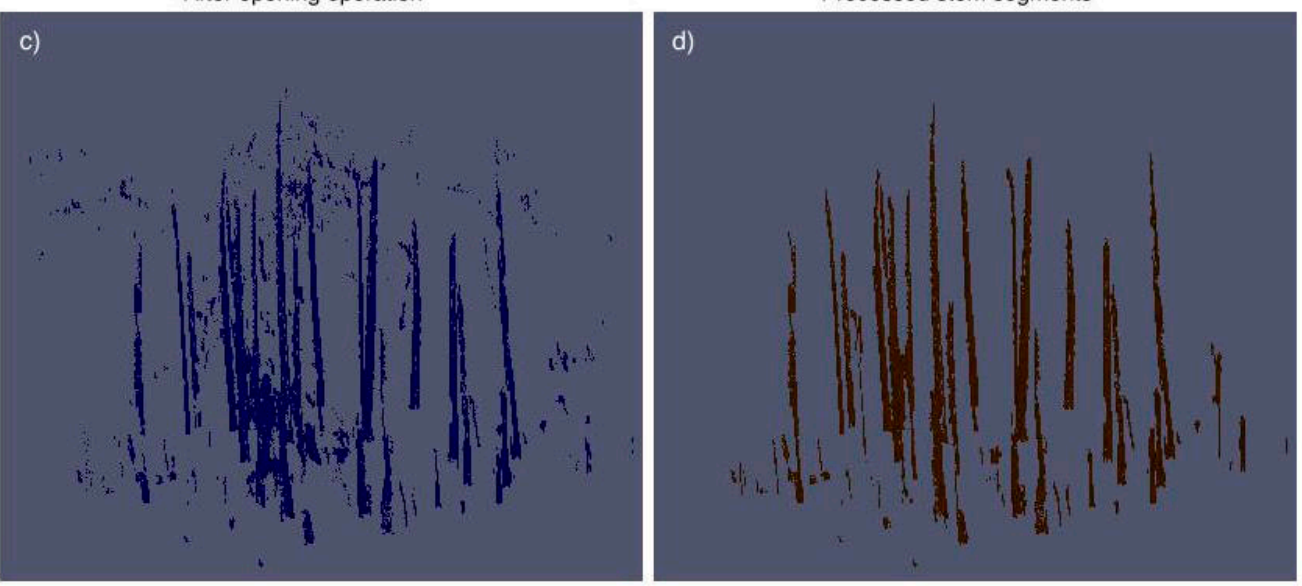

Figure 2. Results from major processing steps illustrated for an example dataset. Image (a) shows the original point cloud colored with RGB values. Image (b) depicts the 3D volume representation of the same dataset with intensity values of scaled transparency for better visualization. Image (c) shows the stem candidate segments after the opening operation and image (d) the final tree stems after logical processing.

\subsection{Morphological Stem Segment Extraction}

The data analysis method starts with the detection of potential tree stem candidates. For this task, techniques from mathematical morphology are applied to 3D volume data. The basis of mathematical morphology largely builds upon the two elementary operations erosion and dilation [37], which can be combined into complex image analysis tools. Both operations aim at probing and measuring the shape and size of objects in 2D or multidimensional images. The probing is done with a structuring element (SE) of specific shape, size, and possibly orientation. Equations (1) and (2) describe erosion and dilation, respectively. Both use notations and terminology from Soille [38] and refer to binary imagery as used in our study. In Equation (1), the set $X$ is eroded by the erosion $\varepsilon$ and a SE $B$. It consists of all points $\mathbf{x}$ so that $B$ is part of $X$.

$$
\epsilon_{B}(X)=\left\{\mathbf{x} \mid B_{\mathbf{x}} \subseteq X\right\},
$$

In Equation (2) the set $X$ is dilated by SE $B$ and results in all points $\mathbf{x}$ with $B$ hitting $X$ when its origin is on $\mathbf{x}$.

$$
\delta_{B}(X)=\left\{\mathbf{x} \mid B_{\mathbf{x}} \cap X \neq \varnothing\right\},
$$

One direct combination of erosion and dilation is the opening operation. Opening is the fundamental operation, which is applied to the volume data for stem detection. Equation (3) defines 
opening as an erosion with the SE $B$ followed by a dilation with the reflected SE. It can be described as testing if the SE fits the image object [38].

$$
\gamma_{B}(X)=\delta_{\breve{B}}[\epsilon(X)]
$$

According to Soille [38], the opening operation can also be described geometrically by the formulation in Equation (4). Geometrically, the opening is the union of all SEs fitting into the set.

$$
\gamma_{B}(X)=\cup_{\mathbf{x}}\left\{B_{\mathbf{x}} \mid B_{\mathbf{x}} \subseteq X\right\}
$$

In order to isolate a tree stem from the volume data, we had to define a template that described its shape in a generalized and simplified form. The challenge was to keep only those cells that were part of a tree stem, while removing all other cells that were unlikely to be part of a stem. Since the stem cells could be directly surrounded by cells belonging to other vegetation parts, the descriptive stem template had to be as strict as possible. Referring to morphological terms, the template represented the SE, which was used for an opening operation. Since a tree stem can geometrically be described as a vertically elongated linear structure, the SE was defined as a three-dimensional line of straight vertical direction. It consisted of a defined uneven number of voxels; it was centered on its middle voxel and it was anisotropic. In order to allow for slight deviations from the straight vertical orientation, the SE was rotated around its vertical axes in a defined number of radii. Figure 3 shows the original straight vertical SE in the upper left corner with a length of 21 voxels. This size of the SE was well suited to detect straight vertical structures from our datasets and was found by experimental testing. The SE was rotated with two increasing horizontal radii around its center, which are expressed by the inclination of the SE in Figure 3. The rotation steps of the small radius with the size of one cell are shown in the top row of the figure. The bottom row shows the same steps for the large radius of two cells. Generally, eight steps for each rotation were used, which referred to the directions of an eight-connected horizontal neighborhood from the center voxel.

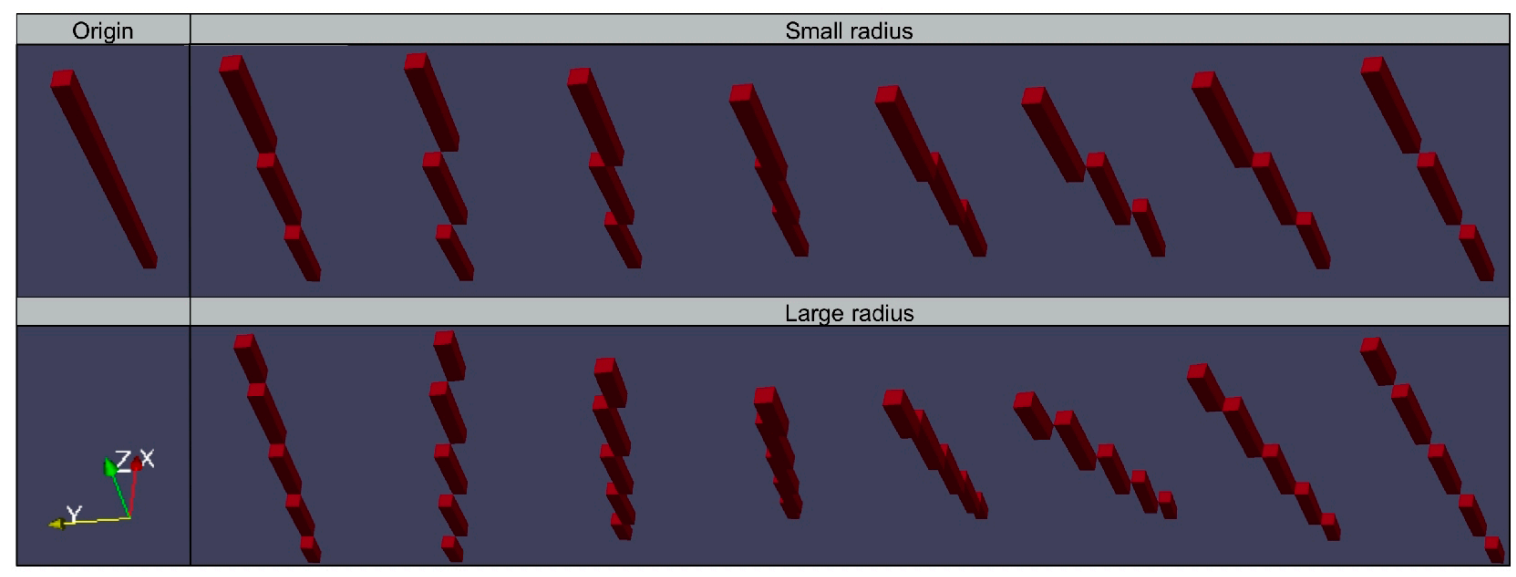

Figure 3. Sequence of the structuring element (SE) rotating with two radii of which each shows eight positions. Starting point is the straight vertical position of the SE in the left corner of the top row. The top row shows the small radius rotation and the bottom row the large radius rotation.

Each individual SE of the series of rotated SEs was used separately for an opening operation of the volume data in order to receive one opened binary voxel grid for each SE, with voxels not fitting the SE being set to 'False'. Finally, all grids were summed and binarized, so that the stem candidate cells with value 'True' from each SE were combined. Figure 2c shows the tree stem candidates after computing and combining the series of opening operations on the volume data. Fragments of noise are still left in the data, which can be seen mainly in the upper part at the height of the mature tree stems. 


\subsection{Logical Segment Processing}

The binary voxel grid, resulting from morphological processing, provided the tree stem candidate segments. A segment was defined as a 3D connected component with a 26-adjacency of grid cells [39] in order to consider the complete neighborhood of each voxel. Labeling these segments made them identifiable for further processing. While some of the stems were already represented by a single segment, the opening operation also resulted in stems being split into multiple segments and also some erroneous fragments which did not refer to tree stems.

The second part of the stem detection method processed these candidate segments by combining those segments referring to the same tree stem and by removing noise. The procedure of this segment processing is described by the flowchart in Figure 4. The segment combination is covered by the partial flowchart on the right side of the figure. After labeling the connected components of the voxel grid, segment combination was conducted in two phases. Firstly, segments, which directly overlapped in the vertical direction, were combined. To determine the overlap, the horizontal projection of each segment was compared against vertical neighbors. In cases where two segments intersected, further conditions had to be fulfilled in order to be combined. These were a maximum vertical absolute distance between both segments, as well as a maximum proportion between the vertical distance in relation to the shortest vertical extension from both segments. While the first criterion guaranteed that even very short segments could be combined, the second criterion allowed the combination of longer and more distinct stem segments, even if they were separated by larger gaps. All thresholds have been found by experimental testing. For the maximum vertical absolute distance, a size of $2 \mathrm{~m}$ provided good results on all plots, and for the maximum proportion of the vertical distance, a factor of 2 was used. The second phase combined segments that did not overlap, but only up to a maximum horizontal shift of one voxel. Also, for these segments, the absolute and relative vertical thresholds were applied.
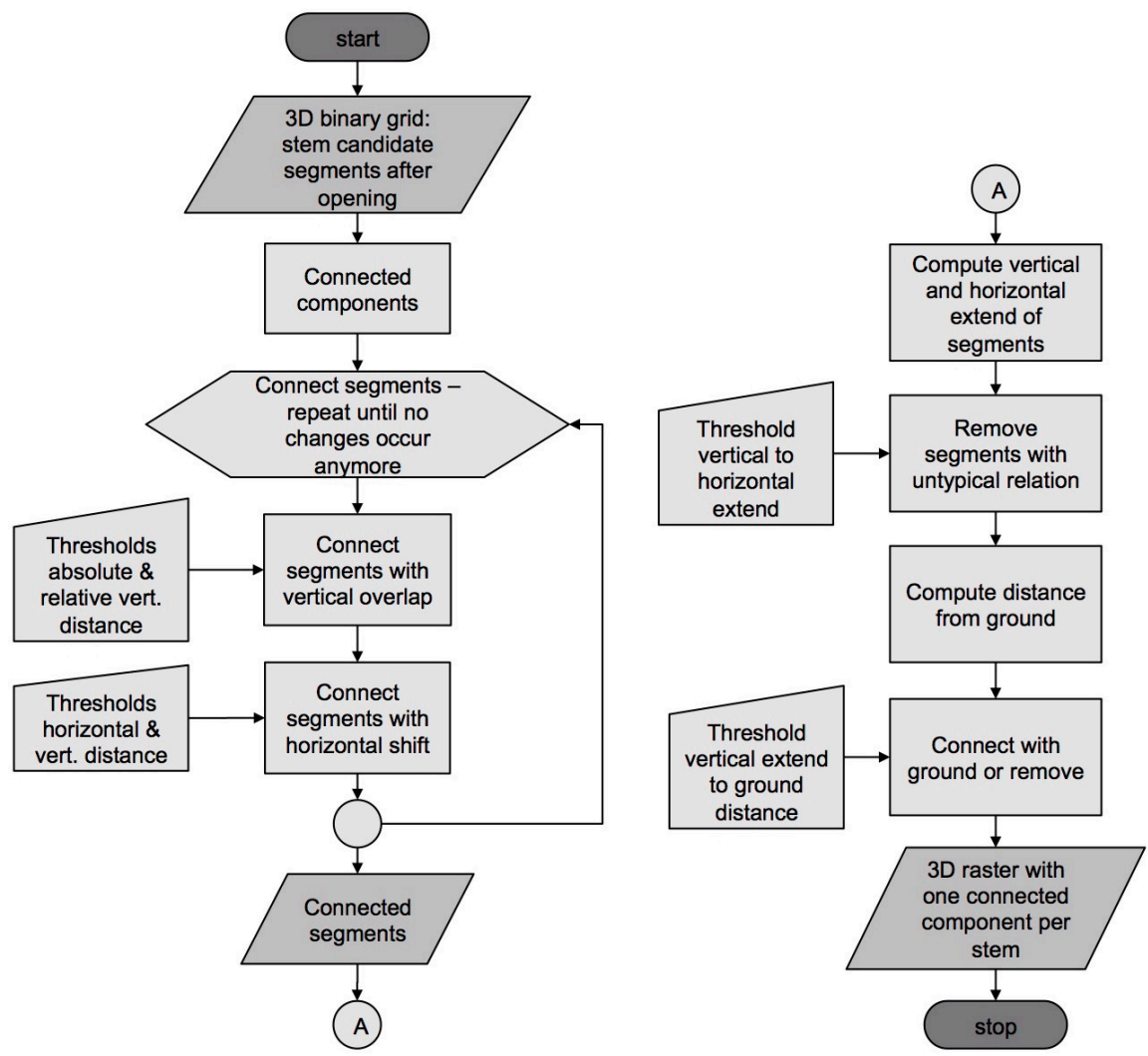

Figure 4. Flowchart for processing of stem candidate segments derived from the opening operations. The left part of the flowchart describes the combination of segments. The right part refers to the logical filtering of segments by their internal dimensions and their relation to the ground. 
The removal of erroneous segments is described by the partial flowchart on the right side of Figure 4 . Few of the primary segments were characterized by an atypically wide horizontal cross section together with a relatively short vertical extension. Those erroneous segments typically refer to fragments of wide and steeply hanging branches from coniferous trees. They could be removed by applying a threshold for atypical proportions of horizontal and vertical extension. For this study, a proportional factor of 3 was used as the threshold for all objects having a horizontal extension of more than $1 \mathrm{~m}$. More often, segments that were not connected to the ground were tested on the proportion of their overall vertical length to their distance from the ground. Depending on that, they were either extended downwards and connected to the ground or considered as noise and removed. If the distance from ground exceeded two times the vertical extension of the segment, the segment was removed from the dataset. In order to avoid errors from objects and vegetation very close to the ground, all data within a minimum distance from the ground has been suspended from calculations. For the experiments in this study, a minimum distance of $50 \mathrm{~cm}$ was used to reduce the influence of grass and other near-ground vegetation.

Figure 5 depicts three examples for the processing of stem segments and noise. The left part of each subfigure shows the original segments in blue after the opening operations and the right part shows same segments in brown after correction. The initial situation in Figure 5a illustrates a stem split into a large continuous segment and a number of very small and disconnected segments above, which are close to each other. Based on the logical rules, all these segments are combined to a single stem, except one small segment in the larger vertical distance at the top. The situation in Figure $5 \mathrm{~b}$ covers a tree stem being split into two long segments but with a relatively large gap in between. Some noise can be seen on the upper left side. The gap is closed based on the relation of segment size to gap size and the noise is removed due to its proportion of segment size and distance from the ground. Figure $5 \mathrm{c}$ is a perspective view of a group of very small tree stems. One of these stems only consists of small and thin disconnected fragments, of which none is attached to the ground. Based on the set of rules, the single pieces are connected and attached to the ground.

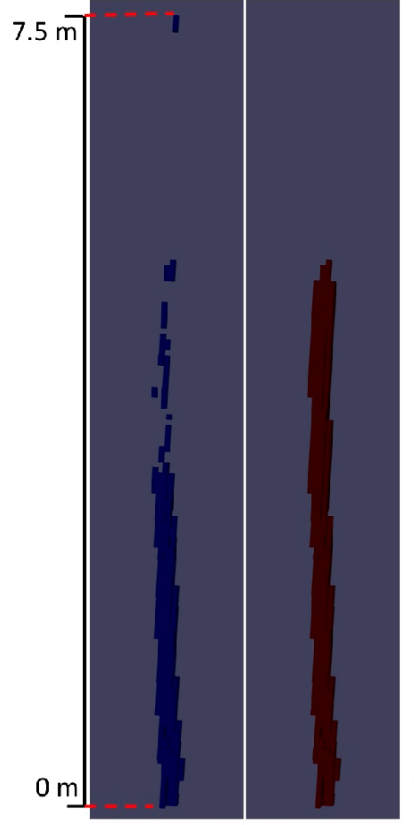

(a)

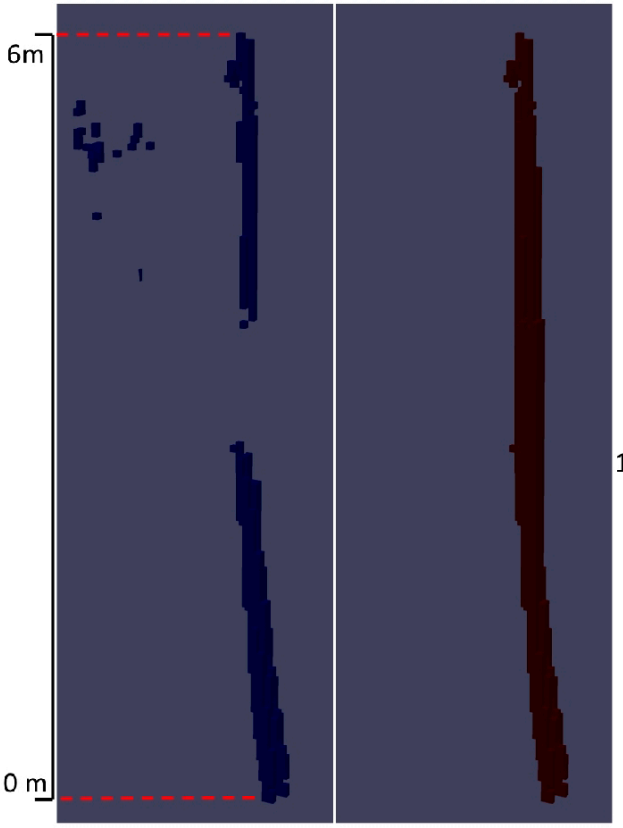

(b)

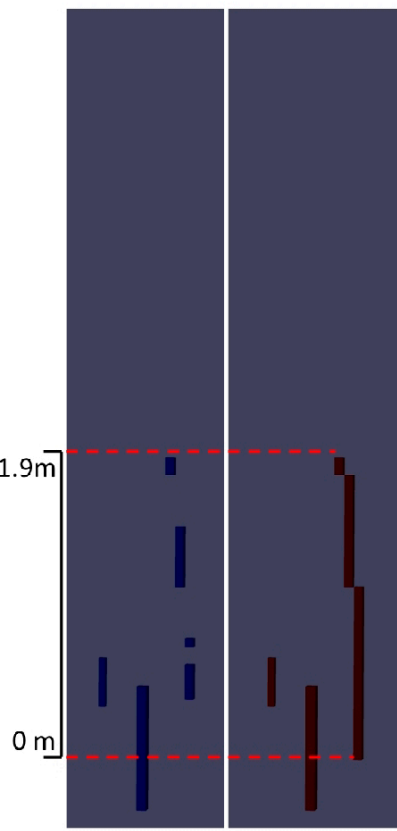

(c)

Figure 5. $(\mathbf{a}-\mathbf{c})$ Examples for the processing of stem candidate segments. The image pairs show the stem candidate segments after morphological opening on the left side in blue color and the final single stem segments after processing on the right side in brown color. The scales vary between the subfigures and the sizes are indicated for the largest extension of the stems. 
As result of the segment processing, a final voxel grid was received, where each connected component referred to a single tree stem. Figure $2 \mathrm{~d}$ depicts the final tree stems of the dataset with noise and erroneous segments being removed.

\section{Results}

The method for tree stem detection was tested on all nine plots and verified using the reference data. For all plots, the same grid cell size and equal algorithm parametrization were used. To compare the geographic coordinate positions of the reference trees with the automatic results, the 3D grid representation of the automatically derived tree stems was projected onto a horizontal 2D raster. The resulting 2D grid included the horizontal projection of each stem labeled with a unique number. While using the same 2D projection of the automatic results, the verification slightly differed between the inventory trees and the regeneration trees due to the type of reference data.

For the inventory trees, the stem position at $1.3 \mathrm{~m}$ height above ground was visually compared against the georeferenced 2D projection of the automatically derived stems. From there, the matching stem positions were counted, while differentiating between tree stems of the inner and the outer circle (see Table 3). A stem was counted as a match if the reference position was within its cross section of the detected stem, or, if it could be clearly assigned to a close-by reference position while excluding any alternative possibility. The latter was required since the positions of the reference trees were based on relative measurements from the fixed GPS position and were potentially affected by the same degree of error as the scanner positions. The detection rate of stems from mature trees, measured by the forest inventory, amounted to more than $97 \%$. It is about the same for tree stem positions from both circles, which differed in their minimum DBHs at $12 \mathrm{~cm}$ and $36 \mathrm{~cm}$.

Table 3. Overview on the verification results for automated tree stem detection using field based reference data. The table lists stem numbers for nine test sites with results separated for mature inventory trees and regeneration trees. The overall detection rates are provided in the bottom row.

\begin{tabular}{|c|c|c|c|c|c|c|c|c|}
\hline \multirow{2}{*}{ Test Site } & \multicolumn{4}{|c|}{ Inventory Trees } & \multicolumn{4}{|c|}{ Regeneration Trees } \\
\hline & Test & Reference & Test & Reference & Test & Reference & Test & Reference \\
\hline 1 & 7 & 7 & 4 & 4 & 8 & 9 & 8 & 9 \\
\hline 2 & 10 & 11 & 6 & 6 & 1 & 2 & 0 & 0 \\
\hline 3 & 10 & 10 & 1 & 1 & 0 & 1 & 0 & 1 \\
\hline 6 & 10 & 10 & 3 & 3 & 9 & 12 & 8 & 10 \\
\hline 7 & 4 & 5 & 4 & 4 & 4 & 4 & 3 & 3 \\
\hline 8 & 4 & 4 & 2 & 2 & 9 & 10 & 7 & 8 \\
\hline 9 & 2 & 2 & 10 & 10 & 15 & 15 & 12 & 12 \\
\hline
\end{tabular}

The detection of tree stems from the regeneration was verified for those trees with a minimum crown top height of more than $1.3 \mathrm{~m}$. This was due to the fact that a certain stem segment length was required in order to be detected by the morphological operation. In addition, the height of the reference trees refers to the tree crown top, which is mostly higher than the distinct part of the stem. A second tree height threshold of $2.0 \mathrm{~m}$ was used for verification in order to test if slightly larger trees could achieve better stem detection rates. Available field reference data for regeneration trees did not include stem positions as it did for the inventory trees. Instead, 2D center positions of the tree crowns, together with the related crown radius, were used to verify the positions of detected stems. Assuming that the stem of a relatively small regeneration tree is horizontally located within the crown radius, each reference tree with an automatically detected stem inside its crown radius was counted as a hit. For a few reference trees, where the stem base was outside the horizontal projection of the 
crown radius, the stem base position was also available from the reference dataset. In such cases, this could additionally help to allocate detected stems to their field reference. Table 3 shows the verification results for regeneration trees, separated by the minimum tree top height. It can be seen that stem detection rates for higher regeneration trees are better than that for smaller trees. However, both have an overall detection rate of well above $84 \%$.

\section{Discussion}

The present study introduced an approach for tree stem detection, which, in its core, is based on 3D morphological operations. The transfer of the original LiDAR point data into a volumetric voxel grid distinguishes this approach from point cloud based stem detection methods $[20,26,33,35]$. The fundament of the method is a series of spatially-variant and directional openings of the complete and original vegetation volume as recorded by the scanner. This effectively removes non-stem parts of the vegetation, while conserving those structures potentially being part of a tree stem. All subsequent processing is based on these morphological stem segments and combines them into connected stem objects or removes erroneous parts.

A technical comparison of the present method with point cloud approaches is generally difficult because they are based on a different data structure in combination with different techniques. Many point cloud approaches fit geometric shapes, mainly cylinders, to the stem reflections $[20,26,35]$ and some others use point classification techniques [33]. While our morphological approach also analyses and probes shapes, the fundamental techniques are different, and we also omit any prior classification. These differences in data structure and analysis compared with most existing solutions were a major motivation for the present study. In contrast to point cloud approaches, the few existing voxel grid based studies allow a more meaningful technical comparison. Hosoi et al. [29] precisely modeled a single tree stem with branches from a high resolution grid. The authors reconstructed the complete stem surface by a neighborhood-based voxel classification, followed by a contour interpolation algorithm. Besides the methodological differences, their approach differs from ours in the handling of occluded stem parts. Founded on high-resolution data of a single tree, their approach is not suitable to manage larger occlusions within datasets from technically challenging forest conditions. The scale and structure of the approach from Brolly et al. [32] is more similar to ours, but differs in the techniques applied. Compared to our series of very strict morphological probing, the authors used a single, relatively tolerant filter. The single and broad filter was applied to homogenous patches of juvenile trees, but the filter design is expected to perform less well in layered forests with stronger occlusion effects. In this context, it also remains unclear if the method of Brolly et al. [32] was applied to trees in a foliated or non-foliated state. The latter would significantly simplify the task and justify such a broad filter design.

The result of the present method was a single connected component for each tree stem. This means that the number of connected components equaled the number of tree stems or trees within a defined area. Furthermore, the method provided the position of each tree stem in geographic coordinates as well as its three-dimensional extension. The algorithm does not intend an accurate reconstruction of the stems. Even if this might be theoretically possible for perfect scans of non-occluded tree stems, in most cases this is precluded by strong shadowing effects from other vegetation parts and perspective effects of the scanner positions. The primary goal of the method is the detection of tree stems by number and position and the combination of segmented stems to single entities. Optionally, the vertical orientation and inclination could be derived for the detected stems, while total stem height might be underestimated due to transition zones between stem and tree crown.

A special challenge of our method is to focus not only on the detection of distinctly shaped stems from mature trees, but also to detect smaller stems from regeneration trees. Furthermore, stems from different forest layers and of strongly varying sizes can be mixed within one dataset. A set of nine spatially separated plots of mixed forest and diverse, often compact, understory layers served as a base for testing and verification. The results show that for the mature trees almost all stems have been 
detected. No difference can be seen between the detection rates of the inner and the outer concentric circle. Since the forest inventory uses a DBH threshold of $12 \mathrm{~cm}$ for the inner circle and $36 \mathrm{~cm}$ for the outer circle, we conclude that at least for stems of $12 \mathrm{~cm} \mathrm{DBH}$ and more constant detection rates can be achieved. It also becomes clear that, even in layered forests with distinct occlusion effects, the presented method produces very reliable results for localizing the position and the number of mature tree stems. Only three of the mature tree stems were not detected. All three errors were caused by very close standing stems, which were merged to a single stem object.

The verification of detected stems from trees of the regeneration layer revealed lower overall detection rates compared to that of the mature trees. This was expected, since a number of factors complicate the situation for the regeneration trees. These factors are more occluding structures within the understory layers, less distinctly developed tree stems compared to mature trees, and smaller exposed relative portions of the tree stem due to the lower crown base in proportion to the total tree height. Considering these difficulties, the overall detection rates for regeneration tree stems was still high at more than $84 \%$. For the validation of the regeneration trees, two groups with different minimum heights of the tree crown tops were considered. This differentiation was undertaken based on the assumption that the impact of the described difficulties depends on the total tree height. The two height groups comprised the frequently used thresholds of $130 \mathrm{~cm}$ and $200 \mathrm{~cm}$. All trees in both groups had a DBH of less than $12 \mathrm{~cm}$ and were not considered in the set of inventory trees. The moderately increased detection rate for regeneration trees from the larger group confirmed our prior assumptions. However, taking into account the already high detection rate in the smaller group, the accuracy increase of only $3.6 \%$ is unlikely to have any practical effects. Compared to the mature trees, the verification of the regeneration layer is theoretically more prone to mismatches, because of closer standing trees and a stronger impact of measurement inaccuracies, however, the considerable high detection rates indicate practically usable results. TLS-based stem detection from the regeneration can provide a reliable measure for quantifying the amount and for localizing the distribution of regeneration in forests. For future application, such TLS derived information could be a useful component for regeneration maps with high spatial resolution. This could replace less accurate approaches currently applied in forest inventory such as, for example, expert based estimates of ground area coverage as proposed by Brang and Duc [40].

The reported detection rates are often difficult to compare with other studies. Many studies dealt with mature trees only and validated specific stem parameters instead of the number and position of detected tree stems [22,35]. Others focused on stem extraction from single isolated trees and did not provide verification on forest stand scale [26,29]. Exceptions are the studies from Kelbe et al. [20] and Xia et al. [33] who worked with heterogeneous stands using single scan perspective data. However, Kelbe et al. [20] only validated the DBH of trees with automatically fitted cylinders. They limited the verification to tree diameters of more than $10 \mathrm{~cm}$ and did not provide detection rates for the number of detected tree stems. Xia et al. [33] reported an average detection rate of $86 \%$ for heterogeneous stands but limited the validation to non-occluded trees visible from the original single scan data. Brolly et al. [32] dealt with stem detection in regeneration patches and avoided mixing stems from different forest layers. They reported detection rates for juvenile trees between $79 \%$ and $90 \%$, but it remains unclear if they were limited to trees in the non-foliated state. In summary, our results show similar detection rates for juvenile trees. For major trees we do not have a reasonable comparison, but due to the almost complete detection, the presented approach should produce competitive detection rates. A major advantage of the present study is that it deals with technically more complex forest structures than most other studies. The larger number of independent test sites additionally underlines the stability of our method. Further, the present method explicitly presented results for small regeneration trees separately from mature tree results. Studies on the applicability of point cloud based methods for regeneration tree detection are still rare. The voxel based data structure not only allows the application of different data analysis techniques for stem detection, it opens the door for combination with other applications in the future. The use of volumetric data structures could 
allow a better exploitation of information from full-waveform LiDAR data [41]. Modeling forests as volumetric voxel data also offers the possibility of applying radiative transfer models to the dataset. Schneider et al. [18] and Gastellu-Etchegorry et al. [42] showed examples for effective implementation of radiative transfer models for volumetric LiDAR data. The position and the vertical extension of all tree stems could also be used as initial information and as a starting point for further developments in individual tree isolation.

\section{Conclusions}

This study presented an advanced approach for tree stem detection based on 3D image analysis techniques. In comparison to many point cloud based approaches, the present method built upon the characteristics of volumetric voxel data by analyzing it with morphological operations. It was shown that such a method achieves high detection rates for both mature trees and trees from the regeneration layer. For mature trees, almost all stems were detected, and for regeneration trees, results showed detection rates of at least $84 \%$. While we cannot see any limitation for mature tree stem detection, for regeneration trees, a minimum tree top height of approximately $130 \mathrm{~cm}$ is recommended for technical reasons. Lower vegetation layers usually do not exhibit clear stem structures and often include grass and shrub layers.

We conclude that the method provided operational results for locating and counting mature tree stems and, with small limitations, also for counting regeneration trees. The results provided the position and number of tree stems of a spatially defined area. In a further step, additional 3D information, such as the inclination of the tree stems, could be derived easily for most stem objects. For future research, we would like to extend the method towards a more complete reconstruction of the original geometric shape of tree stems.

Acknowledgments: This study was conducted within the framework of the Swiss National Forest Inventory, a joint research program of the Swiss Federal Office for the Environment (FOEN) and the Swiss Federal Institute for Forest, Snow and Landscape Research (WSL). The authors would like to thank Natalia Rehush and Björn Dreier for their support in the fieldwork, Christian Ginzler for his expertise in GNSS technology and Susette Haegi for registration of the scans. Special thanks also go to the forest administration of the canton Grisons, Switzerland, who gave important assistance to this project.

Author Contributions: Johannes Heinzel conceived and developed the method, designed the fieldwork, and collected and processed the data. Markus O. Huber conceived and defined the main research objectives, designed the fieldwork, and managed the project. The manuscript was written by Johannes Heinzel with input from Markus O. Huber.

Conflicts of Interest: The authors declare no conflict of interest.

\section{References}

1. Hilker, T.; van Leeuwen, M.; Coops, N.C.; Wulder, M.A.; Newnham, G.J.; Jupp, D.J.B.; Culvenor, D.S. Comparing canopy metrics derived from terrestrial and airborne laser scanning in a Douglas-fir dominated forest stand. Trees 2010, 24, 819-832. [CrossRef]

2. Murgoitio, J.; Shrestha, R.; Glenn, N.; Spaete, L. Airborne LiDAR and terrestrial laser scanning derived vegetation obstruction factors for visibility Models. Trans. GIS 2013, 18, 147-160. [CrossRef]

3. White, J.C.; Coops, N.C.; Wulder, M.A.; Vastaranta, M.; Hilker, T.; Tompalski, P. Remote sensing technologies for enhancing forest inventories: A review. Can. J. Remote Sens. 2016, 1-23. [CrossRef]

4. Reitberger, J.; Krzystek, P.; Stilla, U. Combined tree segmentation and stem detection using full waveform lidar data. In Proceedings of the ISPRS Workshop on Laser Scanning 2007 and SilviLaser 2007, Espoo, Finland, 12-14 September 2007; pp. 332-337.

5. Holmgren, J.; Barth, A.; Larsson, H.; Olsson, H. Prediction of stem attributes by combining airborne laser scanning and measurements from harvesters. Silva Fenn. 2012, 46, 227-239. [CrossRef]

6. Straub, C.; Koch, B. Estimating single tree stem volume of Pinus sylvestris using airborne laser scanner and multispectral line scanner data. Remote Sens. 2011, 3, 929-944. [CrossRef]

7. Stoke, A. Selecting tree species for use in rockfall-protection forests. For. Snow Landsc. Res. 2006, 80, 77-86. 
8. Volkwein, A.; Schellenberg, K.; Labiouse, V.; Agliardi, F.; Berger, F.; Bourrier, F.; Dorren, L.K.A.; Gerber, W.; Jaboyedoff, M. Rockfall characterization and structural protection-a review. Nat. Hazards Earth Syst. Sci. 2011, 11, 2617-2651. [CrossRef]

9. Stoffel, M.; Schneuwly, D.; Bollschweiler, M.; Lièvre, I.; Delaloya, R.; Myint, M.; Monbaron, M. Analyzing rockfall activity (1600-2002) in a protection forest-A case study using dendrogeomorphology. Geomorphology 2005, 68, 224-241. [CrossRef]

10. Dorren, L.; Berger, F.; Jonsson, M.; Krautblatter, M.; Mölk, M.; Stoffel, M.; Wehrli, A. State of the art in rockfall-forest interactions. Schweiz. Z. Forstwes. 2007, 158, 128-141. [CrossRef]

11. Prandi, F.; Magliocchetti, D.; Poveda, A.; De Amicis, R.; Andreolli, M.; Devigili, F. New approach for forest inventory estimation and timber harvesting planning in mountain areas: The SLOPE project. In Proceedings of the ISPRS-International Archives of the Photogrammetry, Remote Sensing and Spatial Information Sciences, XXIII ISPRS Congress, Prague, Czech Republic, 12-19 July 2016; pp. 775-782.

12. Liang, X.; Kankare, V.; Hyyppä, J.; Wang, Y.; Kukko, A.; Haggrén, H.; Yu, X.; Kaartinen, H.; Jaakkola, A.; Guan, F.; Holopainen, M.; Vastaranta, M. Terrestrial laser scanning in forest inventories. ISPRS J. Photogramm. Remote Sens. 2016, 115, 63-77. [CrossRef]

13. Gspaltl, M.; Bauerle, W.; Binkley, D.; Sterba, H. Leaf area and light use efficiency patterns of Norway spruce under different thinning regimes and age classes. For. Ecol. and Manag. 2013, 288, 49-59. [CrossRef] [PubMed]

14. Pommerening, A.; Maleki, K. Differences between competition kernels and traditional size-ratio based competition indices used in forest ecology. For. Ecol. and Manag. 2014, 331, 135-143. [CrossRef]

15. Calders, K.; Newnham, G.; Burt, A.; Murphy, S.; Raumonen, P.; Herold, M.; Culvenor, D.; Avitabile, V.; Disney, M.; Armston, J.; et al. Nondestructive estimates of above-ground biomass using terrestrial laser scanning. Methods Ecol. Evol. 2015, 6, 198-208. [CrossRef]

16. Kankare, V.; Joensuu, M.; Vauhkonen, J.; Holopainen, M.; Tanhuanpää, T.; Vastaranta, M.; Hyyppä, J.; Hyyppä, H.; Alho, P.; Rikala, J.; et al. Estimation of the timber quality of Scots Pine with terrestrial laser scanning. Forests 2014, 5, 1879-1895. [CrossRef]

17. Van Leeuwen, M.; Hilker, T.; Coops, N.C.; Frazer, G.; Wulder, M.A.; Newnham, G.J.; Cukvenor, D.S. Assessment of standing wood and fiber quality using grund and airborne laser scanning: A review. For. Ecol. Manag. 2011, 261, 1467-1478. [CrossRef]

18. Schneider, F.; Leiterer, R.; Morsdorf, F.; Gastellu-Etchegorry, J.-P.; Lauret, N.; Pfeifer, N.; Schaepman, M.E. Simulating imaging spectrometer data: 3D forest modeling based on LiDAR and in situ data. Remote Sens. Environ. 2014, 152, 235-250. [CrossRef]

19. Lovell, J.; Jupp, D.; Newnham, G.; Culvenor, D. Measuring tree stem diameters using intensity profiles from ground-based scanning lidar from a fixed viewpoint. ISPRS J. Photogramm. Remote Sens. 2011, 66, 46-55. [CrossRef]

20. Kelbe, D.; Romanczyk, P.; van Aardt, J.; Cawse-Nicholson, K. Reconstruction of 3D tree stem models from low-cost terrestrial laser scanner data. In Proceedings of the SPIE 8731, Laser Radar Technology and Applications XVIII, 2013, Baltimore, MD, USA, 29 April-3 May 2013.

21. Kelbe, D.; Romanczyk, P.; van Aardt, J.; Cawse-Nicholson, K.; Krause, K. Automatic extraction of tree stem models from single terrestrial lidar scans in structurally heterogeneous forest environments. In Proceedings of the 12th International Conference on LiDAR Applications for Assessing Forest Ecosystems, Canada: SilviLaser, Vancouver, BC, Canada, 16-19 September 2012; pp. 1-8.

22. Eysn, L.; Pfeifer, N.; Ressl, C.; Hollaus, M.; Grafl, A.; Morsdorf, F. A practical approach for extracting tree models in forest environments based on equirectangular projections of terrestrial laser scans. Remote Sens. 2013, 5, 5424-5448. [CrossRef]

23. Yao, T.; Yang, X.; Zhao, F.; Wang, Z.; Zhang, Q.; Jupp, D.; Lovell, J.; Culvenor, D.; Newnham, G.; Ni-Meister, W.; et al. Measuring forest structure and biomass in New England forest stands using Echidna ground-based lidar. Remote Sens. Environ. 2001, 115, 2965-2974. [CrossRef]

24. McDaniel, M.W.; Nishihata, T.; Brooks, C.A.; Salesses, P.; Iagnemma, K. Terrain classification and identification of tree stems using ground-based LiDAR. J. Field Robot. 2012, 29, 891-910. [CrossRef]

25. Raumonen, P.; Kaasalainen, M.; Åkerblom, M.; Kaasalainen, S.; Kaartinen, H.; Vastaranta, M.; Holopainen, M.; Disney, M.; Lewis, P. Fast automatic precision tree models from terrestrial laser scanner data. Remote Sens. 2013, 5, 491-520. [CrossRef] 
26. Hackenberg, J.; Morhart, C.; Sheppard, J.; Spiecker, H.; Disney, M. Highly accurate tree models derived from terrestrial laser scan data: A method description. Forests 2014, 5, 1069-1105. [CrossRef]

27. Bucksch, A.; Fleck, S. Automated detection of branch dimensions in woody skeletons of fruit tree canopies. Photogramm. Eng. Remote Sens. 2011, 77, 229-240. [CrossRef]

28. Gorte, B.; Pfeifer, N. Structuring laser-scanned trees using 3D mathematical morphology. Int. Arch. Photogramm. Remote Sens. 2004, 35, 929-933.

29. Hosoi, F.; Nakai, Y.; Omasa, K. 3-D voxel-based solid modeling of a broad-leaved tree for accurate volume estimation using portable scanning lidar. ISPRS J. Photogramm. Remote Sens. 2013, 82, 41-48. [CrossRef]

30. Raumonen, P.; Casella, E.; Calders, K.; Murphy, S.; Akerbloma, M.; Kaasalainen, M. Massive-scale tree modeling from TLS data. ISPRS Ann. Photogramm. Remote Sens. Spat. Inf. Sci. 2015, \{II\}-3/W4, 189-196. [CrossRef]

31. Kelbe, D.; van Aardt, J.; Romanczyk, P.; van Leeuwen, M.; Cawse-Nicholson, K. Single-scan stem reconstruction using low-resolution terrestrial laser scanner data. IEEE J. Sel. Top. Appl. Earth Obs. Remote Sens. 2015, 8, 3414-3427. [CrossRef]

32. Brolly, G.; Király, G.; Czimber, K. Mapping forest regeneration from terrestrial laser scans. Acta Silv. Lignaria Hung. 2013, 9, 135-146. [CrossRef]

33. Xia, S.; Wang, C.; Pan, F.; Xi, X.; Zeng, H.; Liu, H. Detecting stems in dense and homogeneous forest using single-scan TLS. Forests 2015, 6, 3923-3945. [CrossRef]

34. Van der Zande, D.; Jonckheere, I.; Stuckens, J.; Verstraeten, W.W.; Coppin, P. Sampling design of ground-based lidar measurements of forest canopy structure and its effects on shadowing. Can. J. Remote Sens. 2008, 34, 526-538. [CrossRef]

35. Liang, X.; Kankare, V.; Yu, X.; Hyyppa, J.; Holopainen, M. Automated Stem Curve Measurement Using Terrestrial Laser Scanning. IEEE Trans. Geosci. Remote Sens. 2014, 52, 1739-1748. [CrossRef]

36. Béland, M.; Baldocchi, D.D.; Widlowski, J.-L.; Fournier, R.A.; Verstraete, M.M. On seeing the wood from the leaves and the role of voxel size in determining leaf area distribution of forests with terrestrial LiDAR. Agric. For. Meteorol. 2014, 184, 82-97. [CrossRef]

37. Serra, J. Image Analysis and Mathematical Morphology, v. 1; Academic Press: London, UK, 1982; p. 610.

38. Soille, P. Morphological Image Analysis: Principles and Applications; Springer: Berlin, Germany, 2004; p. 392.

39. Ohser, J.; Schladitz, K. 3D Images of Material Structures: Processing and Analysis; Wiley-VCH: Weinheim, Germany, 2009; p. 325.

40. Brang, P.; Duc, P. Zu wenig Verjüngung im Schweizer Gebirgs-Fichtenwald: Nachweis mit einem neuen Modellansatz. Schweiz. Z. Forstwes. 2002, 6, 219-227. [CrossRef]

41. Stelling, N.; Richter, K. Voxel based representation of full-waveform airborne laser scanner data for forest applications. In Proceedings of the ISPRS-International Archives of the Photogrammetry, Remote Sensing and Spatial Information Sciences XXIII ISPRS Congress, Prague, Czech Republic, 12-19 July 2016; pp. 755-762.

42. Gastellu-Etchegorry, J.-P.; Yin, T.; Lauret, N.; Cajgfinger, T.; Gregoire, T.; Grau, E.; Feret, J.-B.; Lopes, M.; Guilleux, J.; Dedieu, G.; et al. Discrete anisotropic radiative transfer (DART 5) for modeling airborne and satellite specztroradiometer and LiDAR acquistition of natural and urban landscapes. Remote Sens. 2015, 7, 1667-1701. [CrossRef]

(C) 2016 by the authors; licensee MDPI, Basel, Switzerland. This article is an open access article distributed under the terms and conditions of the Creative Commons Attribution (CC-BY) license (http://creativecommons.org/licenses/by/4.0/). 